\title{
Resilience and development: mobilizing for transformation
}

\author{
$\underline{\text { Francois Bousquet }}^{1}, \underline{\text { Aurélie Botta }}^{1}, \underline{\text { Luca Alinovi }}^{2}$, Olivier Barreteau $^{3}, \underline{\text { Deborah Bossio }}^{4}, \underline{\text { Katrina Brown }}^{5}, \underline{\text { Patrick Caron }}^{6}, \underline{\text { Philippe }}^{7}$

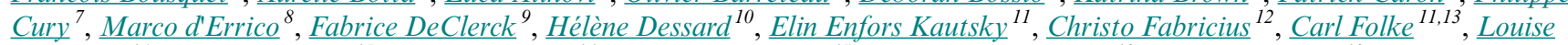

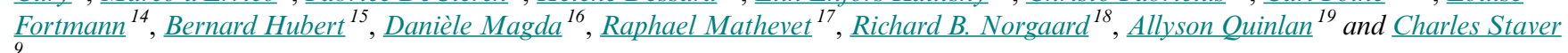

\begin{abstract}
In 2014, the Third International Conference on the resilience of social-ecological systems chose the theme "resilience and development: mobilizing for transformation." The conference aimed specifically at fostering an encounter between the experiences and thinking focused on the issue of resilience through a social and ecological system perspective, and the experiences focused on the issue of resilience through a development perspective. In this perspectives piece, we reflect on the outcomes of the meeting and document the differences and similarities between the two perspectives as discussed during the conference, and identify bridging questions designed to guide future interactions. After the conference, we read the documents (abstracts, PowerPoints) that were prepared and left in the conference database by the participants (about 600 contributions), and searched the web for associated items, such as videos, blogs, and tweets from the conference participants. All of these documents were assessed through one lens: what do they say about resilience and development? Once the perspectives were established, we examined different themes that were significantly addressed during the conference. Our analysis paves the way for new collective developments on a set of issues: (1) Who declares/assign/cares for the resilience of what, of whom? (2) What are the models of transformations and how do they combine the respective role of agency and structure? (3) What are the combinations of measurement and assessment processes? (4) At what scale should resilience be studied? Social transformations and scientific approaches are coconstructed. For the last decades, development has been conceived as a modernization process supported by scientific rationality and technical expertise. The definition of a new perspective on development goes with a negotiation on a new scientific approach. Resilience is presently at the center of this negotiation on a new science for development.
\end{abstract}

Key Words: development; perspective; resilience; social-ecological systems; transdisciplinarity

\section{INTRODUCTION}

Resilience has become a distinct policy objective for sustainable and equitable development. This raises the general question of the use of a scientific concept to support and orient development policies and actions. One specific issue in this science-policy interaction is the existence of different perspectives on the resilience concept and its application. Building on Holling's (1973) seminal work, two distinct research trends are advancing on how the resilience concept could be manifested in policies and specific development programs. On the one hand, there is a large body of work that focuses on the resilience of social-ecological systems (we term this "SES resilience"); on the other hand, there is growing scholarship on what we here term "development resilience."

Scholars have been working on the resilience of social-ecological systems (SES resilience) for the last 30 years (Folke 2006). Resilience here defined as the capacity to cope with change and continue to develop, relates to social-ecological dynamics - e.g., expressed in governance of specific resource systems (agroecosystems, fisheries, forests, rangelands, marine and freshwater ecosystems), and with global issues such as biodiversity conservation, urban growth, economic development, and human security and well-being. According to this perspective, human societies are an integral part of the biosphere, and sustainable social development depends on the continuous generation of essential ecosystem services.

Over the two last centuries, we have entered a new era-the Anthropocene - in which human activities have emerged as a driving force in shaping the biosphere from local to global scales, as reflected by climate change, economic system vulnerability, substantial biodiversity loss, and irreversible ecosystem change (Steffen et al. 2011). There is increasing interest in the transformability of social and ecological systems; i.e., the capacity of society to change the system's state variables when current trajectories become untenable (Westley et al. 2011). As scholars consider that the trajectory of the global ecosystem, the biosphere within which humans are embedded, is actually untenable (Rockström et al. 2009), they get more and more involved in engaging with development issues at different scales, and they interact with development organizations.

More recently, international development and humanitarian organizations have expressed an increasing interest in the

${ }^{1}$ CIRAD, UPR GREEN, F-34398 Montpellier, France, ${ }^{2}$ Global Resilience Partnership, Nairobi, Kenya, ${ }^{3}$ IRSTEA, UMR G-EAU, France,

${ }^{4}$ International Center for Tropical Agriculture (CIAT), Nairobi, Kenya, ${ }^{5}$ College of Life and Environmental Sciences, University of Exeter, UK,

${ }^{6}$ CIRAD, DGDRS, F-34398 Montpellier, France, ${ }^{7}$ Institut de Recherche pour le Développement (IRD), Bruxelles, Belgium, ${ }^{8}$ FAO, Rome, Italy,

${ }^{9}$ Bioversity International, Montpellier, France, ${ }^{10}$ CIRAD, Forêts et Sociétés, F-34398 Montpellier, France, ${ }^{11}$ Stockholm Resilience Centre, Stockholm

University, Stockholm, Sweden, ${ }^{12}$ Sustainability Research Unit, Nelson Mandela University, South Africa, ${ }^{13}$ Beijer Institute, Royal Swedish

Academy of Sciences, Stockholm, Sweden, ${ }^{14}$ UC Berkeley, USA, ${ }^{15}$ INRA, France, ${ }^{16}$ INRA-SAD UMR AGIR 31326 Castanet-Tolosan, France,

${ }^{17}$ Centre d'Ecologie Fonctionnelle et Evolutive, UMR 5175, CNRS-Université de Montpellier-Université Paul-Valéry Montpellier-EPHE,

Montpellier, France, ${ }^{18}$ University of California at Berkeley, USA, ${ }^{19}$ Resilience Alliance 
resilience concept to cope with problems of climate change, political instability, and economic volatility. For these authors, inspired by the work of Alinovi et al. (2008) and the theory of development resilience (Barrett and Constas 2014), development concerns individual agents with basic rights as well as differentiation for improved living conditions, which necessitates differentiation from and adaptation of preexisting, systemsoriented use of resilience concepts. Hence, for these authors, development resilience is the capacity over time of a person, household, or other aggregate unit to avoid poverty when faced with various stressors and in the wake of myriad shocks. The unit is resilient if and only if that poverty avoidance capacity remains high over time. The adoption of this concept has become one of the conditions for granting financing for nongovernmental development actors, particularly in regions weakened by climate change, such as the Sahelian fringe or the Horn of Africa.

Until recently, there has been little interaction between these two trends despite the unprecedented development challengesintransigent poverty and inequality as well as social-ecological unsustainable pathways - which constitute a major threat to human welfare and to global viability. These two schools of resilience thought are increasingly mobilized to address the same problems under the same resilience flag while realizing that resilience definition, methods, and practices employed are partly different.

Transdisciplinary conferences are "third places" (sensu Oldenburg and Brisset [1982]), where converging communities of practice can meet to share perspectives and experiences, evolve new knowledge, and create an amalgam of novel ideas and theories (Wenger et al. 2002). In choosing the theme "resilience and development: mobilizing for transformation," the Resilience 2014 Conference fostered an encounter between these two schools of thought with a focus on resilience, vulnerability, and development of individuals and communities, as well as on resilience as seen through the social-ecological system framework. In this perspectives piece, we reflect on the outcomes of the meeting and document the differences and similarities between the two perspectives as discussed during the conference, and identify bridging questions designed to guide future interactions. The objective of this analysis is not to propose an integrated framework but rather to highlight the main research questions put forward during the conference and how they are approached and formulated from the different perspectives. We ask whether the concept of resilience becomes more robust and practicable through the cross fertilization of the two approaches.

\section{MATERIAL AND METHODS}

Approximately 1000 delegates attended the Resilience 2014 Conference, and approximately 600 oral and poster presentation were accepted. The aims and vision of the conference were oriented toward "resilience and development: mobilizing for transformation," as expressed in the conference objective:

The objective of resilience 2014 is to explore and reinforce the multiple links between resilience thinking and development issues. The concepts of adaptation, transformation and development are central and common to several research communities, including resilience in social and ecological systems, ecological economics, environmental change, farming systems (among others).
Besides, the term resilience is now being used more widely in policy circles and policy debates. Beyond the academic sphere, business and development communities are increasingly using the resilience concept in their discourses. By now they have built their own sets of notions and practices of resilience, although these meanings sometimes may be at odds with scientific interpretations of resilience. Focusing on resilience, but firmly rooted in the belief that a diversity of approaches can inform each other, the conference will offer the opportunity to articulate and debate their specific paradigms, concepts and methodologies. Complex problems require diverse approaches that can generate a constructive debate, and eventually lead to more suitable solutions.

The conference sessions (which included, on average, four presentations) were organized according to the topics shown in Fig. 1.

Most of the authors of this paper were part of the organizing committee or the scientific committee. After the conference, we read the documents (abstracts, PowerPoints) that were prepared and left in the conference database (http://www.resilience2014. org/outputs-outcomes/ppt-presentations) by the participants (approximately 600 contributions), and searched the web for associated items, such as videos, blogs, and tweets from the conference participants. All of these documents, available on the conference website, were assessed through one lens: what do they say about resilience and development? Assigning a category (SES resilience or development resilience) to authors is quite difficult because the organization they belong to (university, NGO, governmental agency, private sector) does not indicate personal orientation. Furthermore, some participants may refer to both categories. At the start, we considered that some participants could be regarded as representatives ("flag holders") of communities of thought and practice, such as the representatives of the Resilience Alliance (SES resilience), or the representatives of the Food and Agriculture Organization of the United Nations (FAO) or the Development Commission of the European community (development resilience). This first analysis is based mostly on the plenary sessions (the videos are available on the conference website). We started with this "community" clustering criteria: the first part of our analysis considers the differences in terms of definition, context, and references to theories and frameworks. We use these criteria to compare the two different perspectives. With these perspectives established, we examine three themes that were significantly addressed during the conference:

- What are the different theories of change (mitigation, adaptation, transformation)?

- The assessment versus the measurement process of change with a specific focus on ecosystem services

- At what scale should resilience be analyzed and actions be taken?

The results we present are derived mainly from a qualitative analysis of conference materials, though we have complemented these with supplementary key literature (citations of the secondary literature are tagged with an asterisk “*”). The 
Fig. 1. Topics of the Resilience 2014 Conference session. Numbers represent the numbers of sessions per category. Group sessions on security and vulnerability include sessions on food security and resilience to natural disasters.

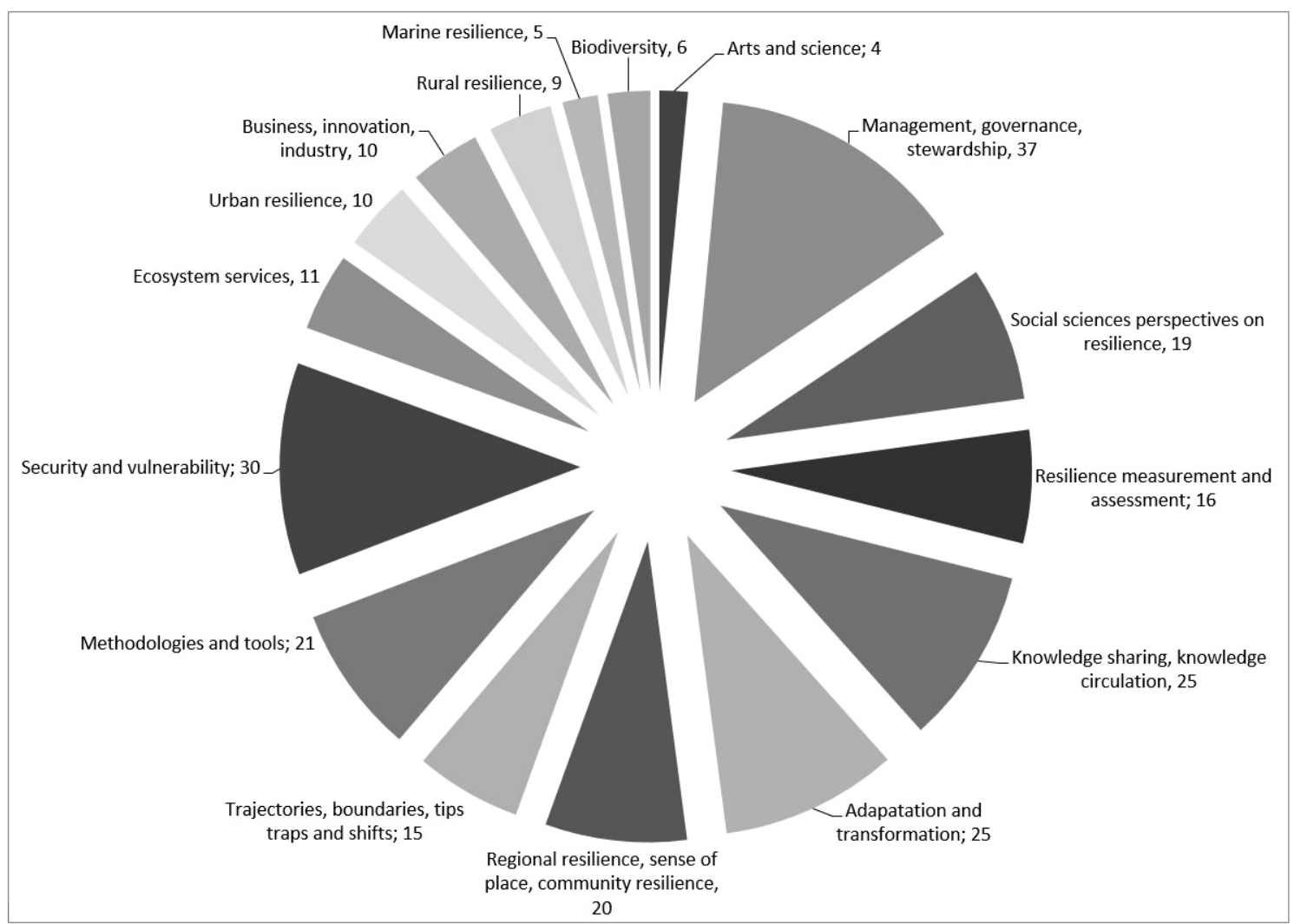

conference contributions we cite were selected because they illustrate the analysis proposed, but the lessons drawn and the debates we report on resulted from a wider set of contributions.

\section{TWO RESILIENCE PERSPECTIVES: DEVELOPMENT AND SOCIAL-ECOLOGICAL SYSTEMS}

We first considered the variety of resilience definitions expressed during the conference. Then we identified the orientations of the two trends, which differ mainly in their response to "resilience of what?".

\section{Definitions}

The first analysis is based on the definitions of resilience highlighted during the conference (source: the PowerPoint files left by the participants) (Table 1). On the SES side, we selected two definitions. The first is provided by Resilience Alliance (http:// www.resalliance.org), and the second is taken from the Intergovernmental Panel on Climate Change (IPCC 2012)*. On the development side, three definitions were used during the conference. The first one comes from the Resilience Measurement Group Technical Working Group, which is a common group of the FAO Food Security Information Network and World Food Program (Hoskins 2014). The second one is proposed by the European Commission (2012) and was presented by Jean-Pierre Halkin during the inaugural plenary session. The third one is the definition of disaster resilience from the Department for
International Development (DFID 2011), and was presented several times within disaster resilience sessions. The definition comparison shows that both sides consider how systems absorb, accommodate, and recover from shocks, although the SES side focuses on the conservation of function, structure, identity, and feedbacks, while the development side focuses mostly on recovery after the shock and the speed of recovery. If we use food security as an illustrative example, development resilience emphasizes response and recovery: the ability of households to respond to unanticipated variability and to learn how to recover quickly from shocks. In contrast, SES resilience approaches food security through social learning, early warning signals, and ecosystem service use. The emphasis is more on how to be prepared and buffer the shock, and how to develop in a way that the system still can keep its identity and functions.

\section{Orientations of each perspective: resilience of what?}

What differs most from development to SES resilience is the field of application and the type of context rather than the definition itself. Development resilience starts from a political and institutional challenge: how to reconcile and articulate development and humanitarian orientations, logics, and actions. Actors involved in humanitarian and development projects that are working separately have regrouped, mainly at the initiative of humanitarian actors who have complained about a lack of development effort for the most vulnerable, which prompts them 
Table 1. Definitions of resilience highlighted during the Resilience 2014 Conference: social-ecological system trend versus development perspective.

\begin{tabular}{|c|c|}
\hline Social-ecological resilience definitions & Development resilience definitions \\
\hline $\begin{array}{l}\text { "Resilience is the capacity of a system to absorb disturbance and } \\
\text { reorganize while undergoing change so as to still retain essentially the } \\
\text { same function, structure, identity, and feedbacks" (http://www.resalliance. } \\
\text { org/resilience). }\end{array}$ & $\begin{array}{l}\text { "The capacity to ensure that stressors and adverse shocks do not have } \\
\text { long-lasting adverse development consequences" (FSIN 2014) }\end{array}$ \\
\hline \multirow{2}{*}{$\begin{array}{l}\text { "Resilience is the ability of a system and its component parts to anticipate, } \\
\text { absorb, accommodate, or recover from the effects of a hazardous event in } \\
\text { a timely and efficient manner, including through ensuring the preservation, } \\
\text { restoration, or improvement of its essential basic structures and functions" } \\
\text { (IPCC 2012). }\end{array}$} & $\begin{array}{l}\text { "Resilience is the ability of an individual, a household, a community, a } \\
\text { country or a region to withstand, to adapt, and to quickly recover from } \\
\text { stresses and shocks" (European Commission 2012). }\end{array}$ \\
\hline & $\begin{array}{l}\text { "The ability of countries, communities and households to manage change, } \\
\text { by maintaining or transforming living standards in the face of shocks or } \\
\text { stresses-such as earthquakes, drought or violent conflict-without } \\
\text { compromising their long-term prospects" (DFID 2011). }\end{array}$ \\
\hline
\end{tabular}

to intervene regularly at the same place with the same communities. The resilience concept has been opportunistically used to keep the focus on countries in serious crises, even in the aftermath of the crisis peak. Resilience is expected to act as a game changer in the programmatic approach in long-lasting crises, integrating humanitarian and development aspects. The resilience concept, which focuses on the ability to undergo multiple shocks, has taken the place of vulnerability, which was previously applied more restrictively to describe a system's sensitivity to disturbance. The focus on resilience involves capacity building to support these multiple shocks. ${ }^{[1]}$

This complementarity between development and humanitarian objectives was shown at the Resilience 2014 Conference inaugural session, with Jean-Pierre Halkin representing the European Directorate General for Development and Cooperation. Halkin stressed that multiple repeated shocks in fragile systems and situations can reverse development progress. Cees Wittebrood, representing the European Humanitarian Aid and Civil Protection Directorate, indicated that the famine in Somalia in 2011 was a turning point in governance. After that crisis, governance systems were adapted to be able to absorb successive shocks, thus avoiding disasters. This led to changes in the programs, which took more into account the long term and focused development more on the most vulnerable. The issue of emergency versus the long-term horizon in the context of food security, at the household level or at the level of social groups and their environment, was addressed by many participants.

To reconcile development and humanitarian aid and to go beyond just the combination of growth and vulnerability paradigms, a new paradigm was needed. The objective was to develop a new conceptual framework for understanding complex contexts in order to be able to address long-term needs of the most vulnerable in a volatile environment. Concretely, the choice has been to focus on households and on their ability to preserve a certain level of well-being (e.g., food security) while withstanding shocks and stresses. Barrett and Constas (2014)*, members of the Food Security Information Network (FSIN) (Hoskins 2014), propose a theory for development resilience (Fig. 2) which looks at a wellbeing trajectory and how this trajectory crosses thresholds which separate three zones (states): the nonpoor zone, the chronic poverty zone, and the zone where humanitarian emergency initiatives are needed. This ability to cross thresholds depends on the livelihood options available to households and their ability to handle risks. This is why most case studies involve a livelihood approach. In line with the studies on food security, four dimensions were considered for improving resilience: availability (physical existence of resources), access (possibility to access the resources), stability (long-term availability and access), and utilization (knowledge and habits). The main orientation from the bridging process between development and humanitarian objectives is the focus on the most vulnerable households and their interactions with natural resources, opening the door for more interactions with SES resilience, which views humans and the environment as interlinked. For instance, through a resilience lens, participants (Sakurai et al. 2014) stressed the fact that vulnerable people need access to natural resources, especially during transition periods. They also insisted that the role of resources in proactively preparing for natural disasters is very different from their role in reactively coping with environmental catastrophes.

Fig. 2. Development resilience theory (Barrett and Constas 2014).

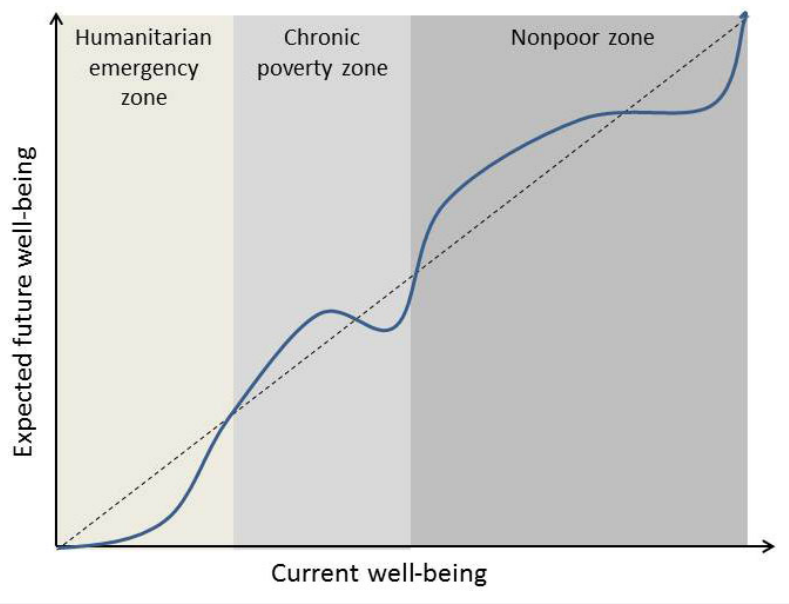


SES resilience contribution to development issues starts also with a focus on trajectories. Starting with a systemic approach which was later on enriched by the developments on complexity, SES resilience considers interlinked social-ecological system trajectories and has a strong tradition in investigating the role of specific actors as well as institutions in this context. An important theoretical contribution here lies in the adaptive cycle, a key concept at the core of resilience (Fig. 3), which contrasts with a more linear vision of development. According to the adaptive cycle, a system proceeds at varying speeds through different phases of growth, release, and reorganization. Cumming (2014) introduces six different mechanisms that might lead to transitions between these different phases of a trajectory. For instance, we select two mechanisms for the conservation phase: (1) systems

Fig. 3. The adaptive cycle. An adaptive cycle that alternates between long periods of aggregation and transformation of resources and shorter periods that create opportunities for innovation is proposed as a fundamental unit for understanding complex systems from cells to ecosystems to societies. For ecosystem and social-ecological system dynamics that can be represented by an adaptive cycle, four distinct phases have been identified: (1) growth or exploitation (r), (2) conservation (K), (3) collapse or release (omega), and (4) reorganization (alpha). The adaptive cycle exhibits two major phases (or transitions). The first, often referred to as the foreloop, from $\mathrm{r}$ to $\mathrm{K}$, is the slow, incremental phase of growth and accumulation. The second, referred to as the backloop, from omega to alpha, is the rapid phase of reorganization leading to renewal. During the slow sequence from exploitation to conservation, connectedness and stability increase and a capital of nutrients and biomass (in ecosystems) is slowly accumulated and sequestered.

Competitive processes lead to a few species becoming dominant, with diversity retained in residual pockets preserved in a patchy landscape. While the accumulated capital is sequestered for the growing, maturing ecosystem, it also represents a gradual increase in the potential for other kinds of ecosystems and futures. For an economic or social system, the accumulating potential could as well be from the skills, networks of human relationships, and mutual trust that are incrementally developed and tested during the progression from $r$ to $K$. Those also represent a potential developed and used in one setting, that could be available in transformed ones. (Image and text from http://www.resalliance.org/adaptive-cycle)

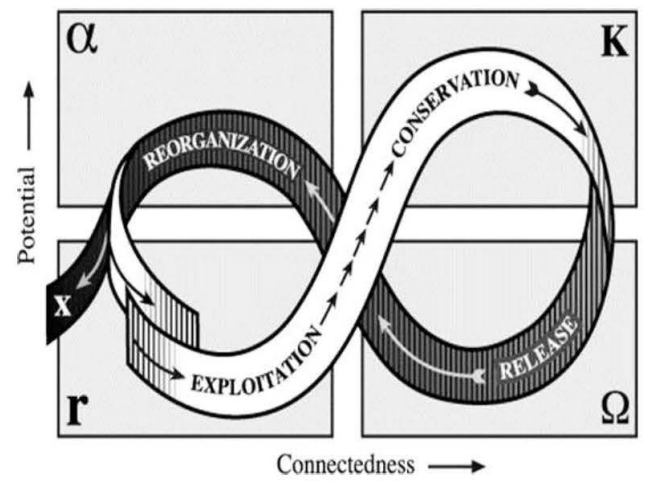

become increasingly vulnerable to infrequent perturbations (e.g., fire, pathogens, pest outbreaks) when they are managed to maximize a quantity (e.g., wood, food production) that is itself vulnerable in one or more critical ways, and (2) systems lose cohesion. Cohesion is maintained by communication, interaction, and spatial proximity_-SES "glue" — and is reduced by interaction costs. This theoretical model is used to "tell" the story of different systems. For instance, Balanzo and Chelleri (2014) describe the four different phases in the adaptive cycle regarding transformation of the Vallcarca neighborhood (Barcelona) in relation to social innovations over the last 10 years. Another example is the interpretation of the crisis of the Malian Cotton Belt through the Panarchy model, a hierarchically nested set of adaptive cycles (Bidou et al. 2014). SES resilience is influenced by a systems perspective and involves development dynamics that are not taking place primarily at the household level. For instance, archaeologists have shown that the rate of agricultural change is inversely related to the vulnerability of assemblages of wild resources in ecosystems to climate shock (Freeman et al. 2014). During one of the plenary sessions, J. Rockström and M. Leach presented an updated metaphor about trajectories (Fig. 4) (Leach et al. 2013). The objective is to identify the "safe and just" pathways for a social-ecological system (see From planetary boundaries).

Fig. 4. Possibilities within the safe and just space: diverse pathways, alternative directions, and varying distributional outcomes (adapted from a plenary presentation).

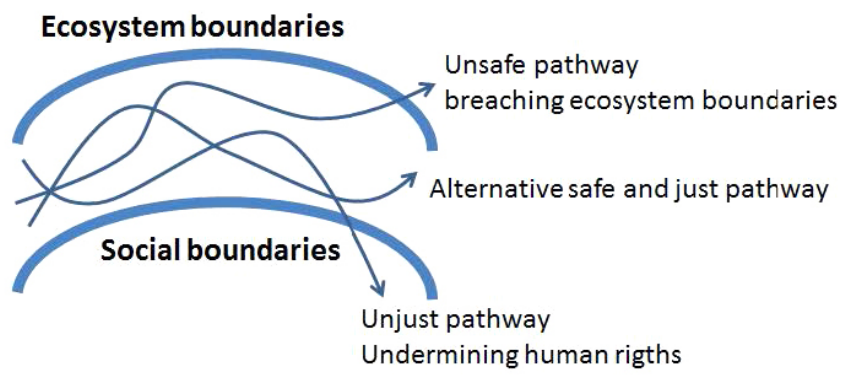

In brief, both domains-SES resilience and development resilience-look at trajectories of change. Their respective interest in resilience reflects the history of their domain (political, disciplinary, and ideological). The main difference is that whereas SES resilience is committed to promoting viable trajectories between social-ecological boundaries, the development resilience domain is committed to promoting positive trajectories in the well-being of the most vulnerable.

\section{Convergences}

Social-ecological system resilience and development resilience converge on several points:

Importance of diversity: For Alvarez et al. (2014), resilience is likely fostered in the form of a "flotilla"-i.e., multiple small actions with a (possibly loosely) defined common purpose; this is illustrated by the "let a thousand flowers flourish" paradigm. Diversity plays a role in different domains. For Basurto (2014), there is a time for institutional emergence and then a time for institutional robustness. Institutional diversity may play a more 
prominent role in the maintenance of institutional robustness than in institutional emergence processes. For Mäkkinen et al. (2014), the response diversity of forage crops has a practically significant potential to be used in adaptive management on farms and in breeding to enhance the ability to cope with climate fluctuation. For Dharmawan and Putri (2014), the livelihood/ income diversification strategy is still considered to be the most important adapted livelihood strategy for rural farm households to maintain survival and resilience.

Resilience is built on a dynamic perspective: Development resilience started with a static view looking at resilience through attributes (endowment, capital, capacity) but is moving toward a dynamic approach. For instance, Lallau and Droy (2014) state that resilience studies do not require only a study of household practices but also household trajectories. They identified three types of trajectories: survival (avoiding the household's destitution), adaptation (organizing to face the consequences of a shock), and resilience (successfully rebuilding the household's most important assets; e.g., the herd).

Tips and traps: Both perspectives recognize the existence of tipping points along the trajectory of the system, which separate different regimes. Traps occur when these tipping points cannot be crossed. According to Frantzeskaki et al. (2014), rigidity traps occur in social-ecological systems when institutions become highly connected, self-reinforcing, and inflexible, as also identified by Gunderson and Holling (2001)*. Poverty traps, unlike rigidity traps, represent a situation in which people are impoverished by circumstances beyond their immediate control (Bowles et al. 2006)*. Novel research on these traps expands on both functional and discursively constructed traps (Frantzeskaki et al. 2014). Examples include traps in urban SES contexts that are brought about by adopting an ecosystem service perspective and by societal discourse that stresses anthropocentrism (for example, the discourse "humans should save nature") (Tidball 2014)

Importance of social capital: Conference participants showed that this factor is also important for conservation and development, confirming and expanding what Aldrich (2012)* has shown on the importance of social capital for postdisaster recovery. For instance, in a study on tiger conservation, Thapliyal et al. (2014) suggest that (a) communities with high social capital are more likely to organize community actions for, or against, tiger conservation; (b) specific community attributes like solidarity, reciprocity and cooperation, networks, and mutual support are crucial; and (c) the current model of tourism had jeopardized the social capital and the capacity of the local communities to organize action by increasing financial disparities. In another study, Ishimoto et al. (2014) show that by accepting mobile phones and enabling communication with others, both near and far, rural people in southern Zambia have activated social capital and transformed the social safety net.

Importance of learning: Several contributions have focused on the importance of learning. A set of contributions deals with the role of communication, either institutional communication, which aims at promoting resilience and its associated concepts, or communication among stakeholders. For example, a field study from Gerger-Swartling and Vulturius (2014) shows that sciencestakeholder interactions are most successful when forest stewards are able to connect climate science with their own experience with extreme events and personal forestry objectives. In experimental settings, Lindahl et al. (2014) show that in communicating groups that can share information and therefore have access to more data points, the likelihood of successful resource management increases in earlier time periods. However, when the first uncertainties about the system are sorted out, this positive management effect of communication is much less marked.

\section{Challenging the resilience approaches}

On the development resilience side, the relationship between development and humanitarian actors has been criticized by some scholars (Daviron et al. 2014). The main criticism is that the introduction of the humanitarian imports the policy of "care" as a new form of governance. The relevance of this criticism is reinforced by the observation that development resilience targets mainly the household level (being part of homogenous communities) and not the social or economic groups level or SES level. For the critics, a policy of care starts from the endorsement of emotional or moral virtues such as compassion to justify decisions made by some for the good of others. The policy of care is also a policy of short timescale because it focuses on the urgent problems to be solved, with an abandonment of long-term development and thus the idea of progress. Long-term progress is replaced by the capacity to cope with shocks. Associated with this policy is the introduction of the "business of care." The critics target, for instance, the introduction of the business of insurances, which coincides with the humanitarian point of entry. However, for Keating (2014), humanitarian aid is a gamble, and risk financing is a safety net when informal safety nets are not sufficient. For her, risk financing is supposed to avoid erosive coping strategies and minimize indirect consequences on development which drive poverty traps. The same critics of a stance of care apply to SES resilience, which increasingly uses the concept of stewardship: the steward is supposed to navigate the social-ecological system and ensure the sustainable use and development of services. The problem is no longer "what are the dynamic ties between humans and nature" but rather "who is taking care of nature?" One conference session (Mathevet and Chapin 2014) discussed the pros and cons of two concepts associated with two perspectives on the extension of care to nonhumans and ecosystems: the concepts of stewardship and ecological solidarity. For the participants, stewardship refers to a hierarchical/external relationship with the biosphere (the steward decides what is good or bad for it), while the ecological solidarity explores the dependencies and interdependencies with others and with nature, and invites to value the social-ecological reliance. The critical issues that remain were how to identify the steward(s), especially in different cultural contexts and at geographical scales, and how solidarity manifests in actions.

The second criticism is the normativity of the concept. For most people in the development resilience group, resilience is perceived as an indexed capacity to a given development outcome. On the other hand, as mentioned by Frantzeskaki et al. (2014), SES resilience has long acknowledged the fact that resilience can be a problem if undesirable states are very resilient. As Petersen (2014) mentions, some communities are trapped in coping or survival mode, where exclusionary practices and inequitable power dynamics are entrenched; this can be referred to as "negatively resilient." In such situations, management intervention may be 
designed to facilitate pushing an undesirable social-ecological system state out of its current one into a new state that can be productive for the community in a different way.

The main criticism regarding SES resilience is the ambiguity about whose resilience (Leach 2014). Who decides on the resilience of whom? Béné, (2014) has warned against the tyranny of resilience because it is not a propoor concept, and the objective of poverty reduction cannot simply be substituted by resilience building. Determining when the resilience of a system is desirable and when it is undesirable is an inherently political, value-laden, and subjective question. Actions to improve resilience for some may undermine resilience and increase vulnerability for others. Who is more resilient and why, and over what timescales? How do institutions shape this? Chiroro and Harrison (2014) present an example of a transfer of vulnerability in Malawi, where they show that protecting some groups from floods increases the flooding risk for others, and where the promotion of irrigation with the introduction of the treadle pump has largely overlooked the livestock sector. Thus, while crop yields and incomes have increased, livestock productivity has decreased substantially, especially as a result of reducing pastures as land is put under irrigation. Furthermore, for Stedman (2014), key regime shifts in social-ecological systems are "in the eye of the beholder" (subjectively) experienced, perceived, interpreted, and acted on. This makes language such as "desirable states" potentially problematic, and the coadaptive management approach, which is usually associated with SES resilience, may suffer from serious problems such as giving power to those who do not want to govern or those who cannot. For Davies et al. (2014), resilience, as a characteristic of social-ecological systems, may be an impediment to development as often as it is facilitator of it, and is not the primary goal of development. Bousquet (2014) discussed the potential "violence of learning": some (scholars and developers) define who should learn, how they should learn, and what they should learn, with the objective of building and maintaining social-ecological resilience. This problem is linked to the general criticism of the global political and economic ideology, which aims at transferring responsibility to the individuals (i.e., the household, which is the main unit in development resilience). However, for many conference participants, science is considered as a framing partner, not a distant deterministic authority. Many scholars insisted on the coproduction of knowledge by different actors (Brugnach and Ingram 2014, Jankowski and Moity Maizi 2014, Tengö et al. 2014a). Scientists and the so-called decisionmakers represent actors among others, and a current issue is whether there is a need for integration of different pieces of knowledge or if different bodies of knowledge should be considered separately.

\section{DIFFERENT THEORIES OF CHANGE: MITIGATION, ADAPTATION, TRANSFORMATION}

At the conference plenary roundtable, Brian Walker, of the Resilience Alliance, stated that one of the main contributions of Resilience Alliance SES resilience scholars is to take feedbacks between ecosystems and social groups into account. But the management of these feedbacks may fail and can lead to very resilient undesirable situations. In this case, it is necessary to break the resilience and engage in system transformation. Therefore, debate on resilience is not only how to adapt to shocks but also how to make a choice between maintaining the system and transforming it. This discussion introduced one of the most important issues highlighted during the conference: i.e., the general question on change and differences between mitigation, adaptation, and transformation. Instead of mitigation, some conference participants such as Sakai (in the industrial field) distinguished between coping, adaptation, and transformation, with coping corresponding to short-term answers, but with adaptation associated with a longer term process: "Short-term coping capacities are milestones to achieve adaptation in the longrun" (Sakai et al. 2014). Some other participants included the concept of transition in the debate (see Models of transformation).

The relationship between mitigation and adaptation was treated in a series of sessions that sought to determine the association between these two models of change while reducing the causes of increasing environmental degradation and promoting adaptation degraded states. However, the conference focus was more on the relationship between adaptation and transformation, which is often presented as an antagonistic choice - either to accept the perturbation and adjust, or determine that an undesirable system must be radically transformed. How can we distinguish between adaptation and transformation? One intellectual thread is to consider transformation as a synergy of adaptations. As stated by Darnhorfer (2014) on organic farming and agroecological stakes, marginal and radical change are difficult to distinguish. Radical change often builds on the synergy of marginal changes: preparation for transformation requires fostering the diversity of networks to allow synergies of local and marginal changes, out of which radically new configurations and practices can emerge. An adaptation cannot be considered in isolation but rather integrated in trajectories of adaptations, also called adaptation pathways. An action on a given object can influence another object. Ferguson and Brown (2014) talk about maladaptation decision: "Action taken ostensibly to avoid or reduce vulnerability that impacts adversely on, or increases the vulnerability of other systems, sectors or social groups." Adaptation pathways aim to inform decision-makers about integrating incremental actions on proximate causes with the transformative aspects of societal change (Wise et al. 2014). Most of the discussions were on this notion of transformation: transforming what and for whom? To what end? Two issues emerged from the conference: what are the transformation models, and what is the role of agency?

\section{Models of transformation}

For Eakin et al. (2014), who gave an example regarding irrigated agriculture, transformations are politically, historically situated, and embedded in ideas about progress and development. Fundamental transformations thus require changes in practices, social relations, and institutional dynamics at multiple scales. Westley (2014) frames the problem of change with the social innovation model: as in technical innovation, social innovation is linked to the discovery/definition of new "social phenomena," which in turn triggers innovative activity and creates the innovation impetus. Several authors used the transition model (Fig. 5) developed for socio-technical systems (Geels 2005)* and applied it to energy and urban agriculture (Frantzeskaki and Loorbach 2014). This well-known model, among other models within the transition studies community, highlights the importance of a multilevel perspective for analyzing the emergence and stabilization of new socio-technical regimes. The 
Fig. 5. Transition model (Image source: Geels 2005).

\section{Increasing structuration of activities in local practices}

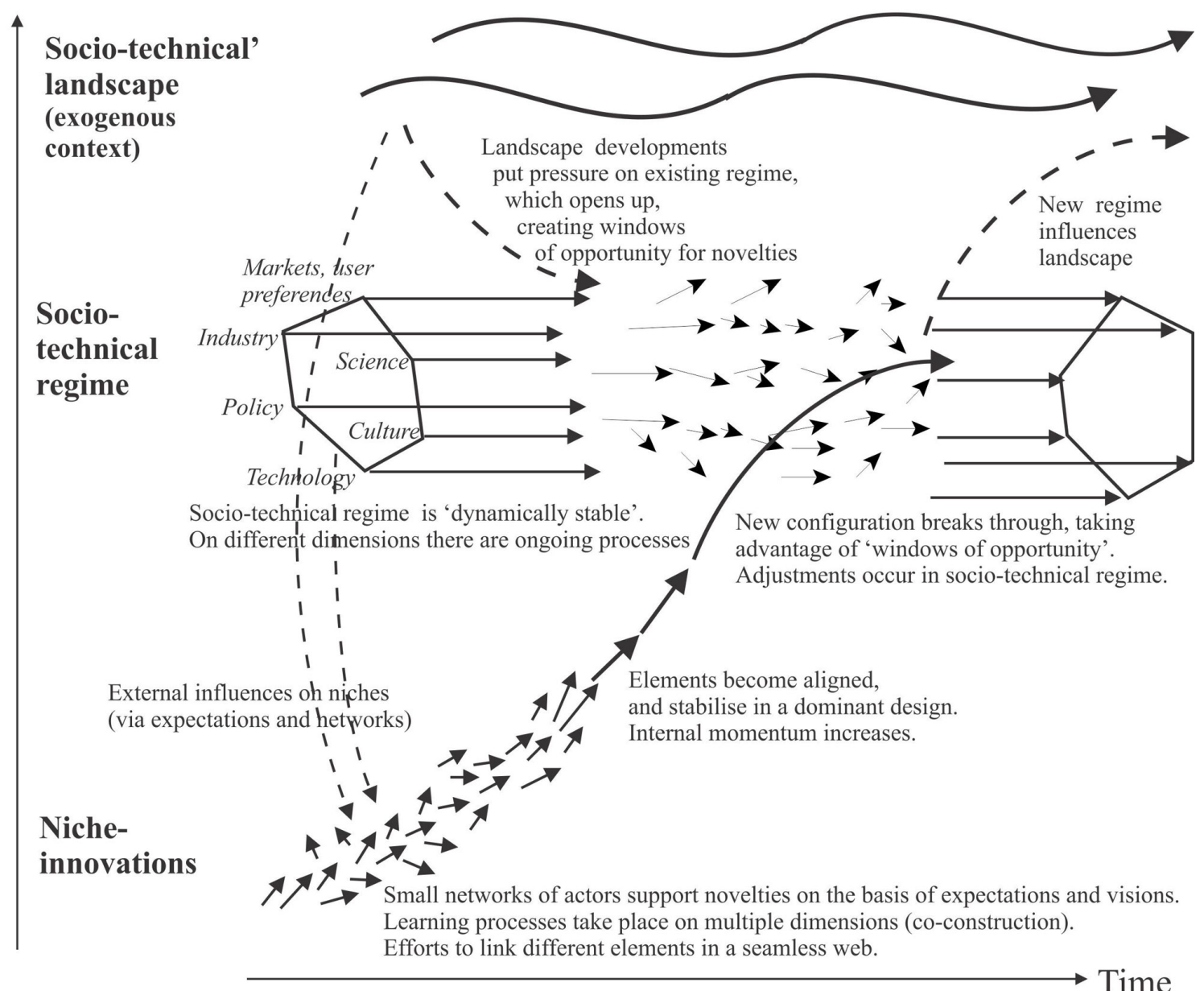

transition model includes the stabilization after change, and thus is not an intermediary process before final transformation.

Several contributions (Abernethy et al. 2014, Chaffin 2014, Cohen 2014) refer to the most influential model of transformation in the SES resilience field, which is the model based on empirical observation proposed by Olsson et al. (2004)*. Three main phases of transformation in social-ecological systems are identified: (1) preparing for transformation which will occur when a window of opportunity is opened, (2) navigating the transition (which in this model is an intermediary stage), and (3) building the resilience of the new direction. An additional contribution which supports this model concerns disaster resilience, and it focuses on disaster as a window of opportunity for transformation (Liu and HochrainerStigler 2014), as already shown in northeastern Honduras (McSweeney and Coomes 2011)* and Mexico (Endfield 2012)*. Preparing for disaster also means being prepared for a window of opportunity. A disaster at a given scale can also reveal that processes at other scales are not running well, thus catalyzing transformation.
Development resilience theory also differentiates models of change, one of them corresponding to transformation (Barrett and Constas 2014). Barrett and Constas (2014) write, "If one's objective is to minimize the likelihood of people falling into either of the less desirable zones - i.e., avoid chronic poverty, much less premature death - then there are three general options for disruptive intervention:...iii) Change the underlying system structure - for example, through changes in cultural, economic, or socio-political institutions or the introduction of new technologies or markets - to induce behavioral change."

\section{Is change related to agency or structure?}

Transformation was the subject of numerous contributions that focused on the "agency" concept, and more precisely on the role of those who make the transformation, such as "cross scale bridging people," "netweavers," "charismatic agents," "entrepreneurs," and "entrepreneurial networks." The contributions at the conference seemed to fuel the dual controversy on change: is change related to agents of change or to the structural context? 
Most contributions on this topic looked at the role of particular agents. Binder et al. (2014) compared two energy transition processes and showed that focusing on one person/one technology leads to a faster transition-but with higher risk and lower resilience. Lallau and Droy (2014) and Boyd et al. (2014) stressed the role of key individuals in information and warning signals. Some participants questioned the role of leaders who were clearly seen as agents of positive transformation. The role of leaders is not unequivocally good: for Cohen (2014), leadership can legitimately block or undermine certain trajectories of change.

In opposition to this focus on agents of change, several researchers focused on structural causes of change. Thus, a novel concept has been developed: i.e., "transformative adaptation," which stresses the importance of understanding the causal structures of vulnerability in different political-economic and environmental contexts as the basis of adaptation (Djoudi and Gautier 2014). For these authors, in contrast to the perspective in which individual decision-makers adapt to natural hazards through a "satisficing" process, transformative adaptation relates to a social process in which political-economic dynamics and social relations determine individuals" "adaptive capability." A group of social scientists proposed to turn to the work of Karl Polanyi (Thompson et al. 2014). In the view of the panel members and participants of this session, "Polanyi's ideas offer a promising basis for a more integrated structural analysis that connects three key dimensions of our current crisis - economic, social-ecological - and three key empirical realities that are (or should be) of normative concern with regard to the transformation agendainequality, instability and unsustainability." Examples are given by Blesh (2014), who shows that change comes from pressure of agrarian movement when intersected with state policy change.

As a trade-off of this dual perspective on change opposing agency and structure, one could conclude that agency needs to evolve jointly with the context of the system it is trying to transform. For Evans et al. (2014), this "critical turn" deconstructs the notion of the "heroic" individual leader to emphasize leadership as a culturally embedded, socially constructed process or a set of practices that are not unequivocally good. For many authors, the transformative agency concept is more about networks of institutional entrepreneurs than about individual leaders. Nowell and Steelman (2014) introduce the "responder network" as unit of analysis, "Collection of individuals, organizations, and agencies that act on behalf of others to minimize harm brought on by the disaster," and recent findings on key network attributes that contribute to the adaptive capacity (the capacity of the network to play a broker role). For Villamayor-Tomas et al. (2014), the two sources of change can be complementary: the response to intense and frequent disturbances tends to rely on the role of leaders, while the response to progressive and/or infrequent disturbances depends on a wider set of conditions.

Collective action mixes the roles of agency and structure. In line with the adaptive comanagement approach, two collective action frameworks/experience were presented at the conference. Collaborative planning (Goldstein et al. 2014) mixes capacity building, planning, and social learning: the goal is to identify how planners can build capacity for communities to define their socialecological system and then engage in deciding what future system is desirable, and what steps should be taken to fulfill these future possibilities. The second experience is the transition town social movement, which has been rising worldwide in the last decade. This movement works toward "localization," while considering the meeting of core needs locally (e.g., food, building materials, energy) as offering huge potential to local economies, and reducing oil vulnerability and carbon emissions. It sees resilience as a desirable state and invites people to take ownership of the process by encouraging creativity and building networks with other organizations. To quote Bohensky et al. (2014), "Scientists may advocate for transformation; community stakeholders may want empowerment."

\section{RESILIENCE METRICS VERSUS RESILIENCE ASSESSMENT PROCESS}

A major theme of the conference was the issue of the measurement and/or assessment of resilience. There is a general debate on metrics versus assessment within and among many scientific fields, in particular in the development and SES resilience domains. A simplified characterization would be that where development resilience focuses on metrics, SES resilience focuses instead on assessment. A more nuanced perspective, however, suggests that this is not so simple and that interactions on this topic can enrich the two domains. A specific subsection is dedicated to the role of ecosystem services as an assessment and measurement process of the SES contribution to development.

\section{Resilience metrics}

Development programs require well-defined mechanisms for evaluating interventions, and more specifically, metrics for quantifying and judging the success of their actions and investments. Thus, the challenge that presents itself is how to measure resilience or how to measure state changes in resilience - its improvement as a response to development action, and if indeed it can or should be measured. According to Davies et al. (2014), we need measures of (1) the state of human development (indicators of well-being, and their changes over time), (2) shocks (measures of the extent and severity of shocks such as droughts), and (3) broader social-ecological conditions (indicators of determinants of resilience). Barnett and Constas (2014)* propose that resilience measurement should be based on poverty measures and should take the predictable path dynamics of well-being into account, based on reliable quantitative and qualitative estimates of the conditional moment functions for well-being. This proposition is consistent with work developed by SES ecologists on warning signals of regime shifts. For many years, SES scholars have collected information on different regime shifts with the aim of comparing them and identifying generic lessons about these shifts (Biggs 2014). Kappel's theory (Kappel et al. 2014), following Scheffer et al. (2012)*, is that before transition arises, variance and autocorrelation in ecological processes rise, whereas recovery rates decrease. Kappel et al. (2014) provide examples of this phenomenon from marine ecosystems. However, social thresholds require a different research approach than do ecological thresholds (Blythe 2014).

Much of the discussion on the topic of metrics at the Resilience 2014 Conference originated from the development groups and tended to focus on food security and crisis impacts. In a plenary session, Alinovi presented his proposition of a resilience index, 
which was the seminal work in this field (Alinovi et al. 2008). In algebraic terms, the resilience index for household "i" can be expressed as follows:

$\mathrm{Ri}=\mathrm{f}($ IFA, A, APS, SSN, S, AC)

where $\mathrm{R}=$ resilience, $\mathrm{IFA}=$ income and food access, $\mathrm{A}=$ assets, APS $=$ access to public services, $\mathrm{SSN}=$ social safety nets, $\mathrm{S}=$ stability, and $\mathrm{AC}=$ adaptive capacity.

Resilience is not observable per se, and is considered as a latent variable depending on the terms on the right hand side of the equation. To estimate $\mathrm{R}$, it is therefore necessary to separately estimate IFA, A, APS, SSN, S, and AC, which are themselves latent variables because they cannot be directly observed in a given survey, but it is possible to estimate them through multivariate techniques. This index is calculated before and after a shock. Since 2008, this FAO Resilience Index Measurement and Analysis has been updated and used in different countries (D'errico et al. 2014). Hoskins and de Schutter (2014) presented the progress being made by the Food and Nutrition Security Resilience Measurement Technical Working Group, which has produced a framing paper that outlines the challenges in measuring resilience. They have also produced a set of resilience measurement principles that echo Alinovi's call for dynamic analysis and reflect systems-based elements (multilevel interactions, rates of change, inherent volatility) as well as the human dimensions (e.g., desirability of system states, people's perceptions, vulnerability connections) that are consistent with an SES resilience perspective.

Yet another type of approach proposed by Béné (2014) is a resilience proxy based on the cost calculated from the sum of anticipation costs plus impact costs plus recovery costs. Béné (2014) postulates "the more resilient an individual, the lower the costs it takes to get through a specific shock." Assigning monetary values as a means of measuring resilience has parallels in the ecosystem services literature, which increasingly recognizes the need to also consider nonmonetary values (see Ecosystem services as a specific concept). SES scholars also aim at quantifying resilience. Some, like Allen et al. (2014), use a discontinuity analysis: "the hypothesis proposes that where ecological processes are sufficiently different in temporal and spatial extent, they may introduce discontinuities (breaks) in the distribution and pattern of ecosystem attributes such as habitat structure and resource availability. These discontinuities in habitat structure and resource availability, in turn, may drive correspondingly discontinuous patterns in species attributes such as body size distributions, occupancy and range size patterns." Nash (2014) tested this proposal and found that on reefs where herbivore assemblages prior to a bleaching event were made up of fishes that had a wider range of body sizes and thus that operated over a broader range of spatial scales, the reefs were more likely to recover to coraldominated states after the disturbance. Thus, analyses that identify the location of discontinuities in habitat or community attributes provide an alternative method for evaluating at least some aspects of resilience.

The recommendations and next steps that follow from the measurement principles appear promising because they account for the concepts that underlie complex systems dynamics and cross-scale interactions, while recognizing the need for both quantitative and qualitative data to understand the causal mechanisms.

\section{The assessment process}

The resilience assessment process finds its foundation in systems analysis, scenario analysis, and participatory modeling processes. The Resilience Alliance's workbook on SES resilience assessment provides a structured guide to understanding system dynamics and their influence on the capacity of the whole system to cope, adapt, and/or transform. Quinlan and Ryan (2014) shared lessons from different workbook applications that employ the following key elements of a resilience assessment: (1) building a conceptual SES model, (2) identifying SES dynamics and feedbacks, (3) identifying thresholds and alternate regimes, (4) describing crossscale interactions, and (5) favoring participatory approaches, learning, and capacity building. In resilience assessment, a main objective is to reconceptualize a system, place, or issue from an alternative perspective; i.e., through a resilience lens and focusing on interactions such that new insights emerge and interventions are better informed. SES resilience scholars often use participatory scenarios to share the different knowledge and perspectives on what could be desirable futures (Waylen et al. 2014). Conceptualizing humans as part of nature and placing people within ecosystems, instead of keeping them separate, represents an important advance in resilience research.

The measurement objective generated discussion among participants in the context of resilience assessment, with its focus on deepening understanding of dynamic system processes (Quinlan et al. 2015). For many, the benefits of measuring resilience involve trade-offs that come about through simplifying a system property that is multifaceted and dynamic. Most metrics proposed to date focus on social variables and the human dimensions of resilience, and have yet to take an integrated SES approach. Many scholars agree that measuring resilience is possible but finding suitable indicators and metrics that retain key attributes of the concept will also need to reflect the fact that resilience is a means and not an end. Understanding exactly what is missing from resilience metrics or what is potentially lost with such a shift in focus from understanding the resilience of a system to measuring it remains to be clearly outlined.

Although some can be dubious about the capacity or usefulness of measuring resilience, an assessment process is often nurtured by the measurement of different values, such as, for instance, the quantification of ecosystem services (see Ecosystem services as a specific concept), or also uses the results of economic experiments which provide measures of human behaviors (Janssen 2014).

Measurement and assessment can also be complementary when the metrics results for a process-based agreement result in shared indicators, aiming at envisioning future scenarios. For instance, Rinaudo et al. (2014) combined the process-based assessment and proposed an index based on three dimensions: (1) the reflexive evaluation of risk and stress, (2) the self-evaluated capacity of transformation, and (3) the envisioning and capacity to craft the future.

Ecosystem services as a specific concept to assess and measure the social-ecological system contribution to development Many influential scholars in the field of SES resilience were deeply involved in the Millennium Ecosystem Assessment process in the 
early 2000s, which supported the development of the ecosystem services concept and its dissemination. More recently, they look at the development issues with the idea that the human condition is tightly linked to environmental conditions, and thus look at how the ecosystem services perspective could serve (or not) the most vulnerable. A framework presented at the conference was the Ecosystem Service and Resilience Framework (Declerck et al. 2014). This framework proposes five principles: (1) meeting the needs of the poor is fundamental, (2) people use, modify, and care for nature, which provides material and immaterial benefits to their livelihoods, (3) cross-scale and cross-level interactions of ecosystem services in agriculture can be managed to positively impact development outcomes, (4) governance mechanisms are vital tools for achieving equitable access to, and provision of, ecosystem services, and (5) building resilience is about enhancing capacity of communities to sustainably develop in an uncertain world. The emphasis here is on agricultural ecosystems as SES that both depend on, and provide, key ecosystem services (rather than the singular focus on natural systems), while also emphasizing human well-being as a response function of ecosystem management. A group of scholars (Biggs et al. 2014) presented recent results that aim to systematically assess and evaluate the empirical evidence supporting seven principles for enhancing the capacity of social-ecological systems to continue delivering desired sets of ecosystem services: (1) maintain diversity and redundancy, (2) manage connectivity, (3) manage slow variables and feedbacks, (4) foster an understanding of SES as complex adaptive systems, (5) encourage learning and experimentation, (6) broaden participation, and (7) promote polycentric governance systems. However, beyond the issue of maintaining flows of ecosystem services, there is a debate about the positive or negative role of the ecosystem service approach in development.

The positive role of ecosystem services: unpacking and measuring human-nature connections

It is generally acknowledged that ecosystems provide major benefits and increase the adaptive capacity of social-ecological systems at multiple scales. According to Petersen (2014), ecosystem services help buffer natural variability and disasters, which is even more essential with climate change. The United Nations Development Program's (UNDP) Biodiversity and Ecosystems Global Framework 2012-2020 enhances resilience to both economic shocks and natural disasters that are intensified by climate change by using natural ecosystems, such as wetlands or forests, to buffer extreme weather events and provide a safety net for rural communities. Lavorel et al. (2014) presented the adaptation services concept as "the benefits to people from increased social ability to respond to change, provided by the capability of ecosystems to moderate and adapt to climate change and variability."

However, as ecosystem services are generated by social-ecological interactions, they require social-ecological governance and planning in order to increase the adaptive capacity and to tip system transitions toward sustainability. Vukamovic et al. (2014) observe that the diversity of critical ecosystem services as a function of societal use does not necessarily involve the ecosystem type, and the key question is how to manage the situation for currently prioritized ecosystem services, while retaining the capacity of the SES to deliver other services in the future.
Tengö et al. (2014b) presented a typology of ecosystem servicesbased poverty alleviation strategies that distinguishes between provisioning, regulating, and cultural services as an intervention focus. For each of these, the authors classify benefits into two major categories: direct, as in food, water, and protection from floods derived from the ecosystem, or income-mediated, where the ecosystem service is sold or provides employment to generate income for the poor. The six resulting clusters are (1) meeting subsistence needs, (2) supporting small-scale agriculture, (3) building functional landscapes, (4) payments for ecosystem services, (5) biocultural revitalization, and (6) nature-based tourism. The framework highlights the diversity of approaches that span multiple ecosystem services, benefits, human well-being components, forms of poverty alleviation, and sectors, and identifies some of the strengths and weaknesses of the different strategies. Based on this, they argue that considering a diversity of potential approaches and adopting multiple complementary strategies are more likely to be successful than the repeated use of any single "correct" strategy.

Hicks and Cinner (2014) compared the perception of various stakeholders on which ecosystem services to prioritize. They observed that the tendency is still to build capacity in economic and knowledge mechanisms by, for example, enabling access to markets, technology, education, awareness, and training programs - but there is also a need for focus on social access mechanisms (social capital, fostering connection to place). They suggest that measuring ecosystem service priorities can highlight key areas of agreement and conflict, both within and across stakeholder groups, to be addressed when communicating and prioritizing decisions. Bezner-Kerr et al. (2014) presented an experimental auction that was used to assign tree-planting contracts. According to the authors, this performance and feedback suggest that ecosystem service auctions can facilitate fairness and transparency, which, for the authors, are often missing from development projects.

\section{The negative role of ecosystem services: a commodification of human-nature relationship}

There is an implicit assumption that ecosystem services will enhance human well-being. But it has been shown and discussed that well-being does not necessarily respond directly to ecosystem changes, and the outcomes have different impacts on different people (Raudsepp-Hearne et al. 2010)*. According to Hamann et al. (2014), areas that exhibit high levels of ecosystem service use coincide with areas that are characterized by overall low human well-being (these are places where ecosystem services cover subsistence needs). McPhearson (2014) argues that ecosystem disservices have been poorly studied and largely overlooked in urban planning, governance, and management. This oversight is problematic because urban greening initiatives - fast becoming a standard component of urban planning and development - may be inadvertently locking in the accumulation of disservices, leading to social-ecological traps that decrease the adaptive capacity of the system.

Most criticism against the ecosystems services approach was concentrated on payment for ecosystem services. Scholars have shown that socio-economic conditions change once payment for ecosystem services is introduced. In some circumstances, strangely enough, they are damaging because they create a new 
socio-economic setting within which the poor get even poorer (this is in contrast to the frequently assumed side objective of payment for ecosystem services: poverty alleviation). According to Kronenberg and Hubacek (2014), problems similar to those that affect resource-rich countries may emerge in the case of ecosystem service-rich economies once payment for ecosystem services (PES) increase at the spatial and monetary scale. The most prominent examples of such problems include rent seeking, unequal bargaining power of buyers and sellers, and volatility of payments, which are all related to the quality of institutions. To ensure the long-term positive impacts of PES, such systems should be carefully designed, while paying particular attention to the distribution of property rights and transparency, decentralization of revenues, and capacity building to ensure further development opportunities. Lansing (2014) argued that PES can be used to provide indirect subsidies for large agribusinesses.

Remig (2014), who was part of the session on Polyani's great transformation, provided a contribution on PES. From an embedded system perspective, how can more resilient socialecological systems and governance arrangements emerge that resist the power of the overarching market system that promotes fictitious commodification? According to Polyanis's orientation, there are important questions regarding how governance solutions for ecosystem services bring about resilience if they do not break with the path dependencies of current forms of commodification. Given the shortcomings of the fictitious commodity character of ecosystem functions, Remig (2014) argues in favor of an analytical shift insofar as it proposes to focus on the behavioral incentive character of PES schemes. The aim is not to commodify nature or to monetarily value the environment but rather to trigger behavioral change and transformation dynamics toward sustainable development, moving from fictitious commodification of "land" to behavioral incentives for ecosystem service management.

Mar Delgado et al. (2014) noted that general welfare depends mainly on common-pool resource extraction, and natural resource protection can provide indirect services to communities (e.g., health, roads, education) but does not generate direct economic incomes. For the authors, quite often government policies run against sustainable socio-environmental practices: the system of payment for ecosystem services restricts production in these areas and pays extremely low prices compared to the benefits provided by these environmental services.

\section{FROM PLANETARY BOUNDARIES TO COMMUNITY RESILIENCE}

"The problems of the Great Barrier Reef, the Galapagos, and elsewhere cannot be solved locally or at any single scale... because they are no longer closed or isolated systems. The key challenge for sustaining coastal social-ecological systems is to design governance structures that can simultaneously address local, regional and global drivers" (Hughes, keynote speaker). We explore the main contributions of SES resilience and development resilience at different scales: global, state, community.

Scholars such as J. Rockström, who belong to SES resilience groups, have been among the main contributors toward development of the Anthropocene concept and its dissemination. Crutzen (2002)* regards the influence of human behavior on the
Earth's biogeochemical processes in recent centuries as so significant that it constitutes a new geological era. An important contribution of SES resilience scholars concerned the development of the planetary boundaries concept. For Rockström et al. (2009)*, resilience is one of the three legacies from which this concept emerged. The framework of "planetary boundaries" is designed to define a "safe operating space for humanity" for the international community, including governments at all levels, international organizations, civil society, the scientific community, and the private sector, as a precondition for sustainable development (Rockström et al. 2009)*. This framework is based on scientific research that indicates that since the Industrial Revolution, human actions have gradually become the main driver of global environmental change. The authors assert that once human activity has passed certain thresholds or tipping points, defined as "planetary boundaries," there is a risk of "irreversible and abrupt environmental change." The scientists identified nine Earth system processes which have boundaries that, provided that they are not crossed, mark the safe zone for the planet. For Leach (2014), planetary boundaries represent a powerful storyline - with a beginning, middle, and end, created by people and institutions - which assigns responsibility and blame, and finally underpins, justifies, and legitimates action. The risk of recognition of the "Earth system" and "safe operating space" as legal entities is that it could legitimize supranational resilience governance, and threaten to become "a pervasive idiom of global governance” (Walker and Cooper 2011)*. Leach (2014), in line with a lot of work in complex systems and resilience thinking, emphasized the concept of pathways with alternative directions and varying distributional outcomes (Fig. 4). Some pathways are unsafe because they cross planetary boundaries; some are unjust because they cross social boundaries. The questions associated with this metaphor of pathways and boundaries are which pathways, whose boundaries, whose goals, who gains, and who loses? Leach's contribution is that pathways should respect the three D's: What "directions" are different pathways headed in? Is there a sufficient "diversity" of approaches? What are the implications for "distribution"? (Leach et al. 2012)*. The development resilience field is not focused at the global scale, although there are two sectors for which global indicators are calculated: poverty and food security. Negotiations are underway for global policies to work on these problems and reduce the levels of these indicators. However, these indicators are not considered as thresholds, as boundaries that should not be crossed for the sake of global survival.

The state level is very important for the development world and is almost absent from SES resilience interest. For several actors in the development world who still believe in the role of the state, the resilience of the state is an objective because, in the present global and neoliberal world settings, the power and legitimacy of states are weakened, which leads to chaotic situations and increases the vulnerability of the most vulnerable. For instance, Abbentheren and Schreiner (2014) consider that the understanding of underlinkages of risks should be integrated into planning to help build the resilience of communities and individuals, as well as the state and its institutions. On the SES side, the state is often just an actor among others to solve problems that are to be tackled at a local or transboundary scale. During the conference, Munaretto and Huitema (2014) considered the 
controversial role of the state. In the natural resource management domain, some scholars have argued that the state-dominated governance model is not well equipped to deal with novel and fast changes, whereas it seems to perform best when change is slow and predictability is high. The argument is that centralized governance systems tend to be inefficient, rigid systems where information flows are distorted and capacity for reaching consensus is low. On the other hand, a state-dominated governance system can count on democratic legitimacy and promotion of general and public interests to distribute power and responsibility for taking action under conditions of very fast change and high unpredictability; e.g., during disasters and crises. In this vein, Munaretto and Huitema (2014) argued that the state still has an important role to play in enabling change toward a desired social-ecological status, and that we need to incorporate the role of the state in discussions on resilience and adaptability. One way to take the criticism of scholars arguing for flexibility into account, while keeping the state in the game, would be to focus on when and how the state should experiment, innovate, learn, and adapt, and what strategies and resources the state possesses and can deploy to experiment, innovate, learn, and adapt. For some scholars, all these resilience micropractices (the self-consciously limited role of government, promoting partnerships through the private sector, stakeholding, active agency, and bottom-up approaches that engage civil society, and institutional reforms) are used to implement a neoliberal governmentality which is a new form of exploitation where local crises are used as a pretext for forcing through market-friendly governance reforms.

As defined by Magis (2010)*, community resilience is the "existence, development and engagement of community resources by community members to thrive in an environment characterized by change, uncertainty, unpredictability and surprise." Both development resilience and SES resilience express a strong interest at the community level. Community is considered as the relevant unit for local resource management; i.e., being able to integrate the local culture (often approached through the "sense of place" proxy) with upper-scale regulations, laws, and incentives. As such, community is considered as the main interlocutor in the comanagement process. For Hanson and Lyon (2014), family and community (place) attachments are privileged drivers of adaptation that offset migration incentives. Place attachment as an adaptation driver can stimulate adaptive transformations. Scholars look at how to enhance community resilience, and the main process to achieve this task is the knowledge exchange or learning process. For Barr and Woodley (2014), the changing relationships between the local state and citizens (largely as a result of government austerity measures) is creating a pragmatic and intellectual space for exploring the role of (re)collectivizing community resilience that draws on notions of "resourcefulness." Indeed, the opening of this space also affords opportunities to reposition expert and lay knowledge regarding "hazard" and "risk" through the development of new modes of social learning about natural hazards and their impacts in an age of anthropogenic climate change and growing resource scarcity. Community-level interventions were considered as positive both by the SES resilience and the development resilience side, although it could have suffered from criticism on the social (who is included) and ecological (does it really prevent depletion) side.
The last plenary session at the conference was a debate between two ecologists, Hughes and Berkes, on global and community scale. These two scales are favored by the participants to address SES or development resilience issues. Nations, states, and governments are often the forgotten scales. Is it, as critics would argue (Joseph 2014), that the resilience project is part of a broader strategy that seeks to govern from a distance and regulate the conduct of states? Or is it the result of a convergence between an ecosystem approach which looks at the scales of threatened ecosystems, and a well-being approach conducted by global agencies which looks at livelihoods at household and community level?

\section{CONCLUSION: EMERGING ISSUES AND RESEARCH THEMES}

Environment, development, and humanitarian cards are being reshuffled at the global as well as local scales. There is a willingness to stimulate the connection between these domains to meet interdependent challenges of food security, poverty, and environmental and human health. There is a diversity of perspectives on these issues, and the resilience concept is considered as a boundary and bridging concept to connect them. It is already operationalized in policies and governance for ecosystem, human, and social well-being, but these efforts target different sectors, at different scales with different tools. The conceptual vagueness (Strunz 2012) has been useful to favor the strategic relationships between different actors of the development world. However, significant amounts of money are invested in application of resilience in development, and there is now a need to clarify the similarities and differences between the perspectives. Several scientific contributions on resilience and development have been produced, and a recent book proposes a very rich synthesis on this topic (Brown 2015)*. The objective of the Resilience 2014 Conference was to offer a dialog and interaction arena for a better understanding of these different perspectives on SES resilience on one hand and development resilience on the other. Based on the analysis of the contributions to the conference, our perspective paves the way for new collective developments on a set of issues:

Who declares/assigns/cares for the resilience of what, of whom? Some look at the resilience of the most vulnerable at the household and community level, and some look at the resilience of the ecosystem at the global and local level. Both analyze the trajectories of their target object, looking at when and how these trajectories cross economic, social-ecological boundaries. The issue of who declares the attainment of resilience and who is in charge of resilience is more controversial. Some favor a coconstruction approach based on a diversity of knowledge systems; some use a more top-down approach to implement resilience policy objectives or management guidelines to favor the resilience of a targeted object, process, or state.

What are the models of transformations and how do they combine the respective role of agency and structure? Several models of change are used by participants: mitigation, adaptation, transition, transformation. The most important development lies in the articulation of the adaptation and transformation model. Some look at transformation as a process of radical change; some argue that transformation is the result of a set of adaptations (developing the concept of transformative adaptation). Most of 
the participants look at agency as the driver of transformation, but some explore the structure of the system to assess whether a window of opportunity is open for change. There is a quest for concepts and frameworks that would integrate structure and agency, as done by O'Brien (2015)*.

What are the combinations of measurement and assessment processes? The commitment to development requires an assessment of the process or a measurement of the outcomes. There is a difference between those who aim to measure resilience as a capacity raised by development projects and those who assess the resilience of a system through the analysis of the system trajectories. However, there is room for interactions between the two approaches because the former are moving toward an understanding of the system dynamics, while the later are including more and more measurements in their assessment process (e.g., the measurement of ecosystem services).

At what scale should resilience be studied? Both scholars working on the resilience of the most vulnerable or on the resilience of social-ecological systems are interested in two scales: the global scale at which global decisions need to be made, and the community level, which is supposed to be the best level for the implementation of resilience modes of governance (learning, best practices, assessment, institutional change).

Social transformations and scientific approaches are coconstructed (Harding 2015)*. For the last decades, development has been conceived as a modernization process supported by scientific rationality and technical expertise. Now that social and ecological change has to be addressed at multiple scales, that multiple sources of knowledge are considered relevant, and that humanitarian objectives are strongly influencing development policies, this development model is deeply challenged. The definition of a new perspective on development goes with a negotiation on a new scientific approach. Resilience is presently at the center of this negotiation on a new science for development.

${ }^{[1]}$ This paragraph is a synthesis of several interviews of key actors who are working on development resilience with different organizations, and readings of these organizations' strategic documents on resilience.

Responses to this article can be read online at: http://www.ecologyandsociety.org/issues/responses. $\mathrm{php} / 8754$

\section{Acknowledgments:}

We thank Martine Antona, Cécile Fovet-Rabot, and the anonymous reviewer for their careful reading of the preliminary version of the text and the improvements they suggested. We also thank the members of the organizing committee and the editorial committee for their contribution to the conference.

\section{LITERATURE CITED}

Abbentheren, B., and K. H. Schreiner. 2014. Strengthening resilience in fragile contexts. Resilience 2014, Montpellier, France.

Abernethy, K., Ö. Bodin, and P. Olsson. 2014. Two steps forward, two steps back: navigating the transitions towards community-based marine resource management in Solomon Islands. Resilience 2014, Montpellier, France.

Aldrich, D. P. 2012. Building resilience: social capital in postdisaster recovery. University of Chicago Press, Chicago, Illinois, USA and London, UK.

Alinovi, L., E. Mane, and D. Romano. 2008. Towards the measurement of household resilience to food insecurity: applying a model to Palestinian household data. Pages 137-152 in R. Sibrian, editor. Deriving food security information from national household budget surveys. Food and Agriculture Organization of the United Nations, Rome, Italy.

Allen, C., K. Nash, T. Spanbauer, and D. Angeler. 2014. Discontinuities and resilience. Resilience 2014, Montpellier, France.

Alvarez, L., D. Foley, and J. Varghese. 2014. The TURAS Project: integrating resilience thinking into urban planning. Resilience 2014, Montpelier, France.

Balanzo, R., and L. Chelleri. 2014. Making sense of the Holling heuristic in urban environments: collective actions and cross scales influences in the transformation of Vallcarca neighborhood (Barcelona). Resilience 2014, Montpellier, France.

Barr, S., and E. Woodley. 2014. Re-configuring resilience for environmental change: politics, practice and the role of scale. Resilience 2014, Montpellier, France.

Barrett, C. B., and M. A. Constas. 2014. Toward a theory of resilience for international development applications. Proceedings of the National Academy of Sciences of the United States of America 111:14625-14630. http://dx.doi.org/10.1073/pnas.1320880111

Basurto, X. 2014. Using fsQCA to study diversity and its effects on emergence and robustness in institutions. Resilience 2014, Montpellier, France.

Béné, C. 2014. Resilience: new Utopia or new tyranny? Reflection about the potentials and limits of the concept of resilience in relation to vulnerability-reduction programmes. Resilience 2014, Montpellier, France.

Bezner Kerr, R., S. Snapp, and V. Ota. 2014. Agrobiodiversity as a key strategy for increased resilience and food sovereignty: reflections from a case study in Malawi. Resilience 2014, Montpellier, France.

Bidou, J., I. Droy, S. Sissoko, and M. Kouressy. 2014. Reading the crisis of the Malian cotton belt through the Panarchy model. Resilience 2014, Montpellier, France.

Biggs, R. 2014. Identifying social-ecological regime shifts: challenges and insights from the Regime Shifts Database. Resilience 2014, Montpellier, France.

Biggs, O., M. Schlueter, and M. Schoon. 2014. Principles for building resilience in social-ecological systems: sustaining 
ecosystem services in a turbulent world. Resilience 2014, Montpellier, France.

Binder, C., A. Von Streit, H. Sauter, and U. Vilsmaier. 2014. The role of resilience for sustainable transformations: insights from energy regions. Resilience 2014, Montpellier, France.

Blesh, J. 2014. Resilience of smallholder farms in the Brazilian Cerrado: an interdisciplinary and participatory assessment framework. Resilience 2014, Montpellier, France.

Blythe, J. 2014. Resilience and social thresholds in small-scale fishing communities. Resilience 2014, Montpellier, France.

Bohensky, E., J. Butler, and Y. Maru. 2014. Operationalising resilience thinking in multi-stakeholder contexts: assessing the catalytic role of scientists. Resilience 2014, Montpellier, France.

Bousquet, F. 2014. Resilience thinking and adaptive comanagement from the development lens: Is there anything new? Resilience 2014, Montpellier, France.

Bowles, S., S. N. Durlauf, and K. Hoff, editors. 2006. Poverty traps. Princeton University Press, Princeton, New Jersey, USA.

Boyd, E., R. Cornforth, and P. Lamb. 2014. Resilience in practice: building resilience to face recurring environmental crisis in African Sahel. Resilience 2014, Montpellier, France.

Brown, K. 2015. Resilience, development and global change. Routledge, London, UK.

Brugnach, M., and H. Ingram 2014. Ways of knowing and the production of blended knowledge when managing for resilience. Resilience 2014, Montpellier, France.

Chaffin, B. 2014. Rebuilding windows of opportunity: adaptive governance and creative disturbance in the Klamath Basin, USA. Resilience 201, Montpellier, France.

Chiroro, C., and E. Harrison. 2014. Whose resilience matters? Lessons learned from irrigation development projects in Malawi. Resilience 2014, Montpellier, France.

Cohen, P. 2014. The role of leadership in navigating change and driving transformation in environmental governance - a case study from Solomon Islands. Resilience 2014, Montpellier, France.

Crutzen, P. 2002. Geology of mankind. Nature 415:23.

Cumming, G. 2014. Rethinking theories of collapse: unravelling the adaptive cycle. Resilience 2014, Montpellier, France.

Darnhofer, I. 2014. Managing the trade-offs between factors that strengthen resilience. Resilience 2014, Montpellier, France.

Davies, J., P. Ericksen, and L. Robinson. 2014. Resilience and sustainable development: insights from the drylands of eastern Africa. Resilience 2014, Montpellier, France.

Daviron, B., C. Béné, V. Ancey, D. Pesche, and F. Bousquet. 2014. Resilience and development: progress for human development or for humanitarian governance? Resilience Alliance 2014. Centre pour la Communication Scientifique Directe, Montpellier, France.

Declerck, F., F. Kizito, and M. McCartney. 2014. Ecosystem service and resilience evaluation of three basins: Volta, Zambezi and Mekong. Resilience 2014, Montpellier, France.
D'errico, M., D. Maxwell, and L. Luca Russo. 2014. Using mixed methods to analyze household and community resilience in conflict affected areas of South Sudan. Resilience 2014, Montpellier, France.

Department for International Development (DFID). 2011. Defining disaster resilience: a DFID approach paper.

Dharmawan, A. H., and E. I. K. Putri. 2014. Smallholder farmers' resiliency under rural-ecological crises: livelihood adapted strategies in Indonesia. Resilience 2014, Montpellier, France.

Djoudi, H., and D. Gautier 2014. Transformative adaptation in a changing world. Resilience 2014, Montpelier, France.

Eakin, H., A. York, C. Rubinos, R. Aggarwal, S. Smith-Heister, C. Bausch, and M. Anderies. 2014. Capacities, institutions and development trajectories affecting the transformation of irrigated agriculture in the urbanizing SW United States. Resilience 2014, Montpellier, France.

Endfield, G. H. 2012. The resilience and adaptive capacity of social-environmental systems in colonial Mexico. Proceedings of the National Academy of Sciences of the United States of America 109:3676-3681. http://dx.doi.org/10.1073/pnas.1114831109

European Commission. 2012. The EU approach to resilience: learning from food security crises. Communication from the Commission too the European Parliament and Council.

Evans, L., C. Hicks, P. Cohen, P. Case, M. Prideaux, and D. Mills. 2014. Deconstructing leadership: the people and processes driving change. Resilience 2014, Montpellier, France.

Ferguson, B., and R. Brown. 2014. Transformation or maladaptation? Exploring the influence of desalination on Melbourne's water resilience. Resilience 2014, Montpellier, France.

Folke, C. 2006. Resilience: the emergence of a perspective for social-ecological systems analyses. Global Environmental Change 16:253-267. http://dx.doi.org/10.1016/j.gloenvcha.2006.04.002

Food Security Information Network (FSIN). 2014. Resilience measurement principles. Towards an agenda for measurement design. World Food Program. Technical Series No. 1.

Frantzeskaki, N., and D. Loorbach. 2014. Transition management as a meta-governance experiment to build energy resilience in European cities. Resilience 2014, Montpellier, France.

Frantzeskaki, N., K. Tidball, and T. Elmqvist. 2014. Tips or traps? Advancing understanding to steer clear of impoverishment traps and tipping points. Resilience 2014, Montpellier, France.

Freeman, J., C. Strawhacker, A. Torvinen, S. Brewington, and G. Hambrecht. 2014. Archaeological studies of the long-term resilience of food supplies to climatic shocks in arid North America and the North Atlantic. Resilience 2014, Montpellier, France.

Geels, F. W. 2005. Technological transitions and system innovations. Edward Elgar, Cheltenham, UK. http://dx.doi.org/10.4337/9781845424596

Gerger Swartling, A., and G. Vulturius. 2014. Using transformative learning to examine the role of climate change 
communication in fostering stakeholder engagement with adaptation. Resilience 2014, Montpellier, France.

Goldstein, B., G. Hill, W. Gregg, S. Kaufman, and A. Olival. 2014. Collaborative resilience in practice. Resilience 2014, Montpellier, France.

Gunderson, L., and C. S. Holling. 2001. Panarchy; understanding transformations in systems of humans and nature. Island Press, Washington, D.C., USA.

Hamann, M., R. O. Biggs, B. Reyers, and T. Elmqvist. 2014. Linking ecosystem services to human well-being in a South African poverty hotspot. Resilience 2014, Montpellier, France.

Hanson, G., and C. Lyon. 2014. Goals of adaptation in place: family, community, place. Resilience 2014, Montpellier, France.

Harding, S. 2015. Objectivity and diversity. Another logic of scientific research. University of Chicago Press, Chicago, Illinois, USA and London, UK.

Hicks, C., and J. Cinner. 2014. An entitlements approach for the analysis of ecosystem service benefits in the western Indian Ocean. Resilience 2014, Montpellier, France.

Holling, C. S. 1973. Resilience and stability of ecological systems. Annual Review of Ecological Systems 4:1-23. http://dx.doi. org/10.1146/annurev.es.04.110173.000245

Hoskins, A. 2014. Resilience measurement for food and nutrition security: process and principles. Resilience 2014, Montpellier, France.

Hoskins, A., and V. de Schutter. 2014. Resilience measurement for food and nutrition security: toward an agenda for harmonized methods and tools and overview of resilience measurement design principles for food and nutrition security. Resilience 2014, Montpellier, France.

Intergovernmental Panel on Climate Change (IPCC). 2012. Managing the risks of extreme events and disasters to advance climate change adaptation. A Special Report of Working Groups I and II of the Intergovernmental Panel on Climate Change. Cambridge and New York.

Ishimoto, Y., H. Miyazaki, U. Tanaka, and C. Umetsu. 2014. Social capital and small-scale farmers in Zambia: an analysis of mobile phone usage. Resilience 2014, Montpellier, France.

Jankowski, F., and P. Moity Maizi. 2014. Modalities and political dimensions of the knowledge co-production for the resilience of socio-ecosystems. Resilience 2014, Montpellier, France.

Janssen, M. 2014. Behavioral experiments of social-ecological systems. Resilience 2014, Montpellier, France.

Joseph, J. 2014. The EU in the Horn of Africa: building resilience as a distant form of governance. Journal of Common Market Studies 52:285-301. http://dx.doi.org/10.1111/jems.12085

Kappel, C., C. Scarborough, M. Hunsicker, and A. Stier. 2014. Building a foundation for managing for tipping points in marine ecosystems. Resilience 2014, Montpellier, France.

Keating, A. 2014. Resilience and risk financing. Resilience 2014, Montpelier, France.
Kronenberg, J., and K. Hubacek. 2014. From poverty trap to ecosystem service curse: a review of the payments for ecosystem services literature. Resilience 2014, Montpellier, France.

Lallau, B., and I. Droy. 2014. Rural households in sub-Saharan Africa: conceptual considerations and methodological issues on resilience. Resilience 2014, Montpellier, France.

Lansing, D. 2014. Exploring linkages between ecosystem service payments, peasant livelihoods, and plantation agriculture. Resilience 2014, Montpellier, France.

Lavorel, S., S. McIntyre, M. Colloff, M. Doherty, H. Murphy, D. Metcalffe, M. Dunlop, D. Williams, R. Wise, and K. Williams. 2014. Operationalising the concept of adaptation services. Resilience 2014, Montpelier, France.

Leach, M. 2014. Power, pathways and planetary boundaries: negotiating green and just transformations. Resilience 2014, Montpellier, France.

Leach, M., K. Raworth, and J. Rockström. 2013. Between social and planetary boundaries: navigating pathways in the safe and just space for humanity. Pages 84-89 in ISSC and UNESCO, editors. World social science report 2013, changing global environments. OECD Publishing and UNESCO Publishing, Paris, France.

Leach, M., J. Rockström, P. Raskin, I. Scoones, A. C. Stirling, A. Smith, J. Thompson, E. Millstone, A. Ely, E. Arond, C. Folke, and P. Olsson. 2012. Transforming innovation for sustainability. Ecology and Society 17(2):11. http://dx.doi.org/10.5751/ es-04933-170211

Lindahl, T., Ö. Bodin, and M. Tengö. 2014. Governing complex commons: the role of communication for experimental learning and coordinated management. Resilience 2014, Montpellier, France.

Liu, W., and S. Hochrainer-Stigler. 2014. Mega-disaster and socioecological transitions. Resilience 2014, Montpellier, France.

Magis, K. 2010. Community resilience: an indicator of sustainability. Society and Natural Resources 23:401-416. http:// dx.doi.org/10.1080/08941920903305674

Mäkinen, H., J. Kaseva, P. Virkajärvi, M. Trnka, and H. Kahiluoto. 2014. An empirical assessment method for resilience through diversification - an application in forage plants. Resilience 2014, Montpellier, France.

Mar Delgado, M., P. Ramos, R. Escalante, and F. Chapela. 2014. Community-based management: trade-offs between sustainability and development. Resilience 2014, Montpelier, France.

Mathevet, R., and T. Chapin, III. 2014. Resilient planet, resilient people: looking for ecological solidarity and stewardship? Resilience 2014, Montpellier, France.

McPhearson, T. 2014. Avoiding urban social-ecological system traps by accounting for both ecosystem services and disservices. Resilience 2014, Montpellier, France.

McSweeney, K., and O. T. Coomes. 2011. Climate-related disaster opens a window of opportunity for rural poor in northeastern Honduras. Proceedings of the National Academy of Sciences of the United States of America 108:5203-5208. http://dx.doi. org/10.1073/pnas. 1014123108 
Munaretto, S., and D. Huitema. 2014. The role of the state in fostering social and ecological resilience and adaptability. Resilience 2014, Montpellier, France.

Nash, K. 2014. Discontinuities, cross-scale dynamics and the organization of ecosystems. Resilience 2014, Montpellier, France.

Nowell, B., and T. Steelman. 2014. Promoting socio-organizational resilience in disaster: toward a measurement framework of network capacity. Resilience 2014, Montpelier, France.

O'Brien, K. 2015. Political agency: the key to tackling climate change. Science 350:1170-1171. http://dx.doi.org/10.1126/ $\underline{\text { science.aad0267 }}$

Oldenburg, R., and D. Brissett. 1982. The third place. Qualitative Sociology 5:265-284.

Olsson, P., C. Folke, and T. Hahn. 2004. Social-ecological transformation for ecosystem management: the development of adaptive co-management of a wetland landscape in southern Sweden. Ecology and Society 9.

Petersen, C. 2014. Incorporating resilience principles into project design in UNDP's ecosystems and biodiversity portfolio. Resilience 2014, Montpellier, France.

Quinlan, A., M. Berbés-Bláquez, J. Haider, and G. D. Peterson. 2015. Measuring and assessing resilience: broadening understanding through multiple disciplinary perspectives. Journal of Applied Ecology 53:677-687. http://dx.doi.org/10.1111/1365-$\underline{2664.12550}$

Quinlan, A., and P. Ryan 2014. Resilience assessment in practice: a dialogue to share insights from case studies and evaluate assessment approaches. Resilience 2014, Montpellier, France.

Raudsepp-Hearne, C., G. D. Peterson, M. Tengö, E. M. Bennett, T. Holland, K. Benessaiah, G. K. MacDonald, and L. Pfeifer. 2010. Untangling the environmentalist's paradox: Why is human well-being increasing as ecosystem services degrade? BioScience 60:576-589. http://dx.doi.org/10.1525/bio.2010.60.8.4

Remig, M. 2014. Ecosystem services through Polanyi's lens: from fictitious commodification to behavioral incentives for cultural ecosystem functions. Resilience 2014, Montpellier, France.

Rinaudo, J.-D., A. Castel, and N. Faysse. 2014. Resilience of groundwater dependent farming systems in a global change context: conceptual framework and empirical study in Morocco. Resilience 2014, Montpellier, France.

Rockström, J., W. Steffen, K. Noone, A. Persson, F. S. Chapin, E. F. Lambin, T. M. Lenton, M. Scheffer, C. Folke, H. J. Schellnhuber, B. Nykvist, C. A. de Wit, T. Hughes, S. van der Leeuw, H. Rodhe, S. Sorlin, P. K. Snyder, R. Costanza, U. Svedin, M. Falkenmark, L. Karlberg, R. W. Corell, V. J. Fabry, J. Hansen, B. Walker, D. Liverman, K. Richardson, P. Crutzen, and J. A. Foley. 2009. A safe operating space for humanity. Nature 461:472475 .

Sakai, P., E. Tompkins, and A. Gouldson. 2014. How vulnerable and resilient are SMEs to climate change? Resilience 2014, Montpellier, France.

Sakurai, T., C. Umestu, and T. Yamauchi. 2014. Integrating climate resilience and disaster resilience for comprehensive food security. Resilience 2014, Montpellier, France.
Scheffer, M., S. R. Carpenter, T. M. Lenton, J. Bascompte, W. Brock, V. Dakos, J. van de Koppel, I. A. van de Leemput, S. A. Levin, E. H. van Nes, M. Pascual, and J. Vandermeer. 2012. Anticipating critical transitions. Science 338:344-348. http://dx. doi.org/10.1126/science. 1225244

Stedman, R. 2014. The reification trap, or "following the data around" - resilience and the sustainability hangover. Resilience 2014, Montpelier, France.

Steffen, W., J. Grinevald, P. Crutzen, and J. McNeill. 2011. The Anthropocene: conceptual and historical perspectives. Philosophical Transactions of the Royal Society A: Mathematical, Physical and Engineering Sciences 369:842-867. http://dx.doi.org/10.1098/ rsta.2010.0327

Strunz, S. 2012. Is conceptual vagueness an asset? Arguments from philosophy of science applied to the concept of resilience. Ecological Economics 76:112-118. http://dx.doi.org/10.1016/j. ecolecon.2012.02.012

Tengö, M., P. Malmer, T. Elmqvist, J. Von Heland, E. Brondizio, and M. Spierenburg. 2014a. Knowledge synergies for the Anthropocene-amultiple evidence base approach. Resilience 2014, Montpellier, France.

Tengö, M., B. Reyers, O. Biggs, L. Dziba, L. Gordon, and G. Peterson. 2014b. A typology of ecosystem service based interventions for poverty alleviation - lessons learned and research needs. Resilience 2014, Montpellier, France.

Thapliyal, S., A. Rastogi, and G. Hickey. 2014. For or against the motion? Assessing the role of social capital in driving community action in the context of tiger conservation in India. Resilience 2014, Montpellier, France.

Thompson, J., M. Göpel, D. Manuel-Navarrete, and M. Remig. 2014. Towards a sustainable and socially just transformation: reflections on Polanyi and the emergence of new forms of governance and social relations in uncertain times. Resilience 2014, Montpellier, France.

Tidball, K. 2014. A gilded trap of our own making: anthropocentric discursive traps as barriers to transformation. Resilience 2014 Montpellier, France.

Villamayor-Tomas, S., M. Cox, I. Pere Ibarra, A. Thiel, and F. Van Laerhoven. 2014. Understanding governance of large freshwater systems: a comparative analysis of environmental governance in national and transnational watersheds. Resilience 20144, Montpellier, France.

Vukomanovic, J., P. Bourgeron, J. Baudry, and K. Krauze. 2014. Managing the Pandora's box: trade-offs between delivering currently prioritized ecosystem services and the capacity to deliver future services. Resilience 2014, Montpellier, France.

Walker, J., and M. Cooper. 2011. Genealogies of resilience: from systems ecology to the political economy of crisis adaptation. Security Dialogue 42:143-160. http://dx.doi.org/10.1177/0967010611399616

Waylen, K., J. M. Ortega, K. Blackstock, and I. Brown. 2014. Scenario planning and futures thinking: a useful tool for community-based management of tradeoffs? Resilience 2014, Montpelier, France. 
Wenger, E., R. A. McDermott, and W. Snyder. 2002. Cultivating communities of practice: a guide to managing knowledge. Harvard Business Press, Brighton, Massachusetts, USA.

Westley, F. 2014. Insights into complex social transformation processes. Resilience 2014, Montpellier, France.

Westley, F., P. Olsson, C. Folke, T. Homer-Dixon, H. Vredenburg, D. Loorbach, J. Thompson, M. Nilsson, E. Lambin, J. Sendzimir, B. Banerjee, V. Galaz, and S. van der Leeuw. 2011. Tipping toward sustainability: emerging pathways of transformation. Ambio 40:762-780.

Wise, R. M., I. Fazey, M. Stafford Smith, S. E. Park, H. C. Eakin, E. R. M. Archer Van Garderen, and B. Campbell. 2014. Reconceptualising adaptation to climate change as part of pathways of change and response. Global Environmental Change 28:325-336. http://dx.doi.org/10.1016/j.gloenvcha.2013.12.002 